DOI: 10.38136/jgon.762977

\title{
Çok Düşük Doğum Ağırlıkıı Bebeklerde Cinsiyetin Prematüre Morbiditeleri ve Mortalite Üzerine Etkisi
}

\section{The Effect of Sex Differences on Premature Morbidities and Mortality in Very Low Birth Weight Infants}

\author{
Șehribanu IȘIK \\ Fatma Nur SARI ${ }^{1}$ \\ Mehmet BÜYÜKTIRYAKi ${ }^{1}$ \\ Ömer ERTEKIN \\ Evrim Alyamaç DiZDAR ${ }^{1}$ \\ Cüneyt TAYMAN ${ }^{1}$
}

\author{
(1) Orcid ID:0000-0003-2999-059X \\ (1) Orcid ID:0000-0003-4643-7622 \\ (1) Orcid ID:0000-0001-8937-4671 \\ (1) Orcid ID:0000-0002-7846-7634 \\ (1) Orcid ID:0000-0001-8956-0917 \\ (1) Orcid ID:0000-0002-9970-0714
}

${ }^{1}$ Ankara Șehir Hastanesi, Yenidoğan Kliniği, Ankara, Türkiye

\section{öz}

Amaç: Bu çalışmanın amacı çok düşük doğum ağırlıkı (ÇDDA) bebeklerde cinsiyetin prematüre morbiditeleri ve mortalite üzerine etkisini değerlendirmektir.

Gereç ve yöntemler: Bu retrospektif çalışmaya, 2013-2017 yılları arasında Zekai Tahir Burak Kadın Sağı̆̆ı Eğitim ve Araştırma Hastanesi'nde doğarak yenidoğan yoğun bakım ünitesinde izleme alınan, gebelik haftası 30 haftadan küçük tüm prematüre bebekler alındı. Her iki cinsiyetteki bebekler; demografik özellikler, neonatal morbiditeler ve mortalite açısından karşılaştııılı. Ardından bebekler gebelik haftalarına göre ( $<28$ hafta, $>28$ hafta) alt gruplara ayrılarak neonatal sonuçlar tekrar değerlendirildi.

Bulgular: Toplam 757 bebeğin verileri analiz edildi. Çalışma grubunda ortalama gebelik yaşı $27.7 \pm 1.4$ hafta, ortalma doğum ağılığı $1023 \pm 241$ gr ve bebeklerin $\% 53$ 'ü erkek, \%47'si kız idi. Çalışmaya alınan tüm hastalarda kız ve erkek cinsiyet karşlaştırıldığında respiratuvar distres sendromu, patent duktus arteriozus, nekrotizan enterokolit, orta-ağır bronkopulmoner displazi ve laser tedavisi gerektiren prematüre retinopati sıklığı benzer bulundu. Ancak erkek bebeklerde kızlara göre ciddi intraventriküler kanama (IVK), mortalite ve ciddi IVK veya mortalite daha yüksek oranda saptandı. Çalışma grubu $<28$ hafta ve $>28$ hafta olarak tabakalandırıldı. Erkeklerde 28 hafta altında mortalite ile ciddi IVK veya mortalite oranı daha fazla iken; >28 haftada erkelerde sadece ciddi IVK oranının daha fazla olduğu görüldü.

Sonuç: Preterm bebeklerin klinik izleminde göz önünde bulundurulması gereken önemli faktörlerden biri de cinsiyet olup, fizyopatolojik süreç ve neonatal olumsuz sonuçların azaltılmasına yönelik cinsiyete özgü ek stratejler geliştirlmesi ile ilgili çaış̧malara ihtiyaç duyulmaktadır.

Anahtar Kelimeler: Prematüre, cinsiyet, morbidite, mortalite

\section{ABSTRACT}

Objective: The aim of this study is to evaluate the effect of gender on premature morbidity and mortality in very low birth weight (VLBW) infants.

Materials and Methods: In this retrospective study, infants gestational age of less than 30 weeks admitted to the neonatal intensive care unit of Zekai Tahir Burak Maternity and Teaching Hospital between January 2013 and December 2017 were evaluated. Infants of both sexes; demographic characteristics, neonatal morbidities and mortality were compared. The infants were then divided into subgroups according to their gestational weeks ( $<28$ weeks, $>28$ weeks) and neonatal outcomes were reevaluated.

Results: Data of 757 infants were analyzed. In the study group, mean gestational age was $27.7 \pm 1.4$ weeks, mean birth weight was $1023 \pm 241 \mathrm{~g}$ and $53 \%$ of the babies were male and $47 \%$ were female. Comparing the genders, the frequency of respiratory distress syndrome, patent ductus arteriosus, necrotizing enterocolitis, moderate-severe bronchopulmonary dysplasia and premature retinopathy requiring laser treatment were similar in all patients included in the study. However, severe intraventricular hemorrhage (IVC), mortality and severe IVC or mortality were higher in males than females. The study group was stratified as $<28$ weeks and $>28$ weeks. It was observed that mortality and severe IVC or mortality were higher in males at $<28$ weeks and serious IVC was higher in males at $>28$ weeks. There was no difference in terms of other premature morbidities in females and males in both gestational week groups.

Conclusion: Gender is one of the important factors to be considered in the clinical follow-up of preterm infants, and studies are needed to develop additional sex-specific strategies to reduce the physiopathological process and neonatal adverse outcomes.

Keywords: Preterm, gender, morbidity, mortality 


\section{GíRiş}

Prematürite, mortalite ve uzun dönem morbidite için önemli bir risk faktörü olmaya devam etmektedir. Son yıllarda obstetrik ve neonatal bakım konusundaki ilerlemeler ile birlikte, aşırı prematüre bebeklerde hayatta kalma oranı artış göstermektedir $(1,2)$. Mortalite oranlarında azalmanın yarıya yakınını respiratuar distress sendromu (RDS) ve bronkopulmoner displaziye (BPD) bağlı ölümlerdeki azalmanın oluşturduğu bildirilmektedir (3). Ayrıca, geç başlangıçlı sepsis, prematüre retinopatisi (ROP), ve ciddi intraventriküler kanama (IVK) gibi morbiditeler de azalmıştır (4).

Literatürde bazı çalışmalarda preterm bebeklerde cinsiyetin mortalite ve morbidite oranlarında farklılık ile ilişkili olduğu bildirilmiştir. İlk kez 1971 yılında Naeye ve arkadaşları mortalite oranlarında erkek cinsiyet dezavantajını iddia etmişlerdir (5). Konuyla ilgili yapılan sonraki çalışmalarda bu cinsiyet ilişkisini destekleyen yayınlar olduğu gibi, farklıık olmadığını iddia eden yayınlar da mevcuttur (6-9). Bu nedenle cinsiyet ile mortalite ve morbidite arasında ilişki olup olmadığının netleştirilmesi konusu hala araştırmaya açıktır. Çalışmamızda <30 gestasyon haftasında doğmuş olan bebeklerde mortalite ve morbidite oranları ile cinsiyet ilişkisinin değerlendirilmesi amaçlandı.

\section{GEREÇ VE YÖNTEMLER}

Çalışmamız için Tıpta Uzmanlık Eğitim Kurulu ve yerel etik kurul onamı alınmıştır. (30.05.2018-27). Bu retrospektif çalışmaya, Ocak 2013 ve Aralık 2017 yılları arasında hastanemizde doğarak yenidoğan yoğun bakım ünitesinde izleme alınan, doğumda gebelik haftası 30 haftadan küçük tüm prematüre bebekler alındı.

Bebeklerin demografik ve klinik verileri dosya kayıtlarından elde edildi. Major konjenital anomalisi olan, cinsiyeti belirlenemeyen bebekler ile çoğul gebelikler ve verilerine ulaşılamayan hastalar çalışma dışı bırakıldı. Bebeklerin gebelik haftası, annelerin son adet tarihi, erken dönem prenatal ultrasonografi (US) verileri veya doğum sonrası Yeni Ballard skoru ile belirlendi. Bebeğin cinsiyeti, doğum ağırlığı, baş çevresi ve Apgar skoru, CRIB (Clinical risk index for babies) skoru, prematürite ilişkili morbiditeleri olup olmadığı (RDS, patent duktus arteriyozus (PDA), IVK, nekrotizan enterokolit (NEK), ROP, orta-ağır BPD, mekanik ventilasyon (MV) süresi, taburculukta vücut ağırlığı ve taburcu edildiği postnatal günü, ve mortalite bilgileri dosya verilerinden kaydedildi.
Ünitemizde preterm bebeklerin beslenme ve bakımı, RDS, BPD, ROP, PDA tanıları ve yönetimi; Türk Neonatoloji Derneği rehberlerindeki öneriler doğrultusunda yapıımaktadır. BPD, doğumda gebelik yaşı <32 hafta olan prematüreler için PM 36. haftada ve gebelik yaşı $\geq 32$ hafta olan prematüreler için postnatal 28. günde veya bunlardan daha erken gerçekleşirse taburculuk zamanında; hafif BPD ek oksijen gereksiniminin olmamasl; orta BPD <\%30 ek 02 gereksiniminin olmasl; ağır $\mathrm{BPD} \geq \% 30 \mathrm{O} 2$ gereksinimi ve/veya pozitif basınç gereksinimi olması olarak tanımlandı. Ciddi ROP grubuna, lazer gerektiren hastalar alındı (10-16). NEK olguları, Bell's kriterlerine göre evrelendirildi (17). IVK tanısı kranial US ile konularak, evrelendirme Papille sınıflamasına göre yapıldı. İntraventriküler kanama grubuna Evre 3 ve 4 IVK'sı olan hastalar alındı (18).

Çalışmaya alınan yenidoğanlar cinsiyetlerine göre iki gruba ayrıldı ve gruplar demografik özellikler, neonatal morbiditeler ve mortalite açısından karşılaşııııldı.

\section{İstatistiksel analiz}

Kategorik verilerin karşılaştırılmasında ki kare testi kullanıldı. Devamlı değişkenlerin normal dağılıp dağılmadığı Kolmogorov Smirnov testi ile değerlendirildi. Normal dağılan değişkenler student $t$ testi kullanılarak, normal dağılmayan değişkenler ise Mann Whitney $U$ testi kullanılarak analiz edildi; $p$ değerinin $<0.05$ olması istatistiksel anlamlılık olarak kabul edildi. Sonuçlar ortalama \pm standart sapma veya ortanca (çeyrekler arası aralık) olarak verildi.

\section{BULGULAR}

Toplam 757 bebeğin verileri analiz edildi. Çalışma grubunda ortalama gebelik yaşı $27.7 \pm 1.4$ hafta ve doğum ağırlığı $1023 \pm 241$ g idi. Bebeklerin 402'si (\%53) erkek, 355'i (\%47) kız idi. Doğumda gestasyon haftası, doğum ağırlığı, baş çevresi, 1. ve 5. dakika Apgar skoru, CRIB skoru puanı açısından erkek ve kız bebekler benzerdi. MV süresi, taburculukta yaş ve vücut ağırlığı açısından da cinsiyet grupları arasında farklııık bulunmadı (Tablo 1). 
Tablo 1. Bebeklerin cinsiyet gruplarına göre özellikleri

\begin{tabular}{|l|l|l|l|}
\hline & Erkek (n=402) & Kız (n=355) & p \\
\hline Gebelik haftası, hafta * & $28(26-29)$ & $28(26-29)$ & 0.59 \\
\hline Doğum ağırlığı, g * & $1040(885-1240)$ & $995(820-1170)$ & 0.63 \\
\hline Baş çevresi, cm* & $26(25-27)$ & $26(24-27)$ & 0.72 \\
\hline 1. dk Apgar skoru * & $5(4-6)$ & $5(4-6)$ & 0.11 \\
\hline 5. dk Apgar skoru * & $7(6-8)$ & $7(6-8)$ & 0.33 \\
\hline CRIB skoru * & $3(2-6)$ & $3(1-6)$ & 0.26 \\
\hline MV süresi, gün * & $1(0-5)$ & $1(0-4)$ & 0.07 \\
\hline Taburculuk vücut ağırlığı, g* & $2155(1935-2470)$ & $1975(1800-2250)$ & 0.99 \\
\hline Taburculuk gün * & $62(48-80)$ & $64(49-80)$ & 0.65 \\
\hline
\end{tabular}

*Ortanca (çeyrekler arası aralık) Mekanik ventilasyon (MV)

Çalışmaya alınan tüm hastalarda kız ve erkek cinsiyet karşılaştırıldığında RDS, PDA, NEK, orta-ağır BPD ve lazer gerektiren ROP sıklığı benzer bulundu. Ancak erkek bebeklerde kızlara göre ciddi IVK ( $p=0.007)$, mortalite $(p=0.04)$ ve ciddi IVK veya mortalite $(p=0.002)$ daha yüksek oranda saptandı (Tablo 2). Tablo 2. Bebeklerin cinsiyet gruplarına göre morbidite ve mortalite oranları

\begin{tabular}{|l|l|l|l|}
\hline & Erkek & Kiz & $\mathbf{p}$ \\
\hline RDS (\%) & 64.2 & 58.9 & 0.14 \\
\hline PDA (\%) & 40.6 & 46.1 & 0.12 \\
\hline İVK (\%) & 59.6 & 55.3 & 0.22 \\
\hline Ciddi IVK (\%) & 14 & 8 & $\mathbf{0 . 0 0 7}$ \\
\hline NEK (\%) & 2 & 1.4 & 0.52 \\
\hline ROP (\%) & 7 & 9.6 & 0.21 \\
\hline Orta-ağır BPD (\%) & 15.8 & 15.2 & 0.85 \\
\hline Ölüm (\%) & 21 & 15.5 & $\mathbf{0 . 0 4 1}$ \\
\hline Ölüm ya da IVK (\%) & 64.4 & 57.8 & 0.06 \\
\hline Ölüm ya da ciddi İVK (\%) & 29 & 19 & $\mathbf{0 . 0 0 2}$ \\
\hline Ölüm ya da NEK & 22.6 & 16.5 & 0.036 \\
\hline Ölüm ya da ciddi ROP & 27.2 & 23.8 & 0.28 \\
\hline Ölüm ya da BPD (\%) & 33 & 27.4 & 0.082 \\
\hline
\end{tabular}

Bronkopulmoner displazi (BPD), intraventriküler kanama (IVK), nekrotizan enterokolit (NEK), patent duktius arteriyozus (PDA), prematüre retinopatisi (ROP), respiratuar distres sendromu (RDS)

Çalışma grubu doğumda gestasyon haftası $<28$ hafta ve $\geq 28$ hafta olacak şekilde tabakalandırıldı.. 28 gestasyon hafta altında olan erkeklerde mortalite $(p=0.03)$ ile ciddi IVK veya mortalite $(p=0.01$ ) oranı daha fazla iken; $\geq 28$ gestasyon haftada doğan erkeklerde ise sadece ciddi IVK ( $p=0.02$ ) oranının kızlara göre daha fazla olduğu görüldü. Her iki gebelik haftası grubunda kız ve erkeklerde diğer prematüre morbiditeleri açısından fark saptanmadı (Tablo 3).
Tablo 3. Bebeklerin cinsiyet ve gestasyon haftalarına ( $<28$ hafta ve $\geq 28$ hafta) göre morbidite ve mortalite oranları

\begin{tabular}{|l|l|l|l|l|l|l|}
\hline & \multicolumn{3}{l}{$<\mathbf{2 8}$ hafta } & \multicolumn{2}{l}{ hafta } \\
\hline & Kiz & Erkek & $\mathbf{p}$ & Kiz & Erkek & $\mathbf{p}$ \\
\hline RDS (\%) & 70 & 75.3 & 0.27 & 50 & 54.5 & 0.36 \\
\hline PDA (\%) & 55.6 & 51.1 & 0.39 & 38.4 & 31.5 & 0.14 \\
\hline İVK (\%) & 68.1 & 78.5 & 0.023 & 44.9 & 43.2 & 0.72 \\
\hline Ciddi IVK (\%) & 14.4 & 21.5 & 0.08 & 2.5 & 7.5 & $\mathbf{0 . 0 2 2}$ \\
\hline NEK (\%) & 2.5 & 1.1 & 0.42 & 0.5 & 2.8 & 0.12 \\
\hline ROP (\%) & 16.8 & 15.7 & 0.81 & 4.9 & 1.6 & 0.065 \\
\hline Orta-ağır BPD (\%) & 26.2 & 22 & 0.44 & 7.3 & 11.6 & 0.15 \\
\hline Ölüm (\%) & 22.5 & 32.8 & $\mathbf{0 . 0 3 4}$ & 9.6 & 10.8 & 0.68 \\
\hline Ölüm ya da IVK (\%) & 72.5 & 83.9 & 0.014 & 46 & 47.4 & 0.76 \\
\hline Ölüm ya da ciddi IVK (\%) & 30.6 & 43.5 & $\mathbf{0 . 0 1 3}$ & 10.1 & 16.4 & 0.060 \\
\hline Ölüm ya da NEK & 24.4 & 32.8 & 0.08 & 10.1 & 13.6 & 0.27 \\
\hline Ölüm ya da BPD (\%) & 41.2 & 46.8 & 0.30 & 16.2 & 21.1 & 0.197 \\
\hline Ölüm ya da ciddi ROP & 36.4 & 45.7 & 0.09 & 14.1 & 12.2 & 0.56 \\
\hline
\end{tabular}

Bronkopulmoner displazi (BPD), intraventriküler kanama (IVK), nekrotizan enterokolit (NEK), patent duktius arteriyozus (PDA), prematüre retinopatisi (ROP), respiratuar distres sendromu (RDS)

\section{TARTIŞMA}

Çalışmamızda gebelik haftası $<30$ hafta olan erkek bebeklerde kızlara göre ciddi IVK, mortalite, ciddi IVK veya mortalite daha yüksek oranda saptandı. Erkeklerde 28 gestasyon haftasının altında mortalite ile ciddi IVK veya mortalite oranı daha fazla iken; 28 hafta ve üzeri gestasyon haftasında erkeklerde ciddi IVK oranının daha fazla olduğu görüldü. Çalışmamızda RDS, PDA, NEK, orta-ağır BPD, ve ciddi ROP sıklığı kız ve erkek bebeklerde benzer bulundu. Yapılan klinik araşıımalarda, fetal ve neonatal dönemde başlayan ve erişkinliğe uzanan süreçte, cinsiyet farklııklarına dayalı beyin ve nöronal fizyolojide farklılık olduğu gösterilmiştir. Travmatik beyin yaralanmasını takiben ölen vakaların retrospektif değerlendirildiği bir çalışmada, benzer şiddette yaralanmalarda erkeklerde mortalite oranı daha fazla bulunmuş, bu durum hasarlanmaya verilen cevap ve fizyolojik onarım mekanizmalarında bir farklılık olduğunu düşündürmüştür (19). Benzer şekilde serebral palsi ve perinatal gelişim sırasındaki nörolojik hasara bağlı sorunlar erkeklerde daha sık görülür (20). Erkek preterm infantlar benzer gebelik yaşındaki kızlara kıyasla IVK ve beyaz madde hasarına karşı daha savunmasız; onarım süreçleri, iyileşme ve nihai nörogelişimsel sonuçları da daha kötü görünmektedir (21). Serebral kan akımı düzenlemesi gibi fizyolojik düzenlemeler de cinsiyete göre değişir, ancak yaşa göre değişkenlik göstermektedir. Prematüre bebeklerde, kızlarda serebral kan akımı benzer gestasyonel ve postnatal yaştaki erkeklerden daha düşüktür (22). Ancak, yetişkin dönemde ise kadınlarda erkeklerden daha yüksek beyin kan akımı vardır (23). Bu durumun mekanizması tam olarak anlaşılmamış olmakla birlikte, prematüre bebeklerde serebral kan akımı otoregülasyonunun nispi olgunlaşmamışlığı, nispe- 
ten düşük serebral kan akışına sahip kızlarda germinal matriks veya intraventriküler kanama insidansının daha az olmasını açıklayabilir.

Araştırmalarda, erkek dezavantajının hormonal çevre farkııığı ile de ilişkili olabileceği şeklinde yorumlar da bulunmaktadır. Erkek fetüslerde dişilere oranla daha yüksek düzeyde testosteron düzeyleri bildirilmiş ve bu durumun vasküler gelişimi etkileyerek nörolojik morbiditeleri arttırabileceği iddia edilmiştir $(24,25)$. ÇaIsşmamızda da erkek bebeklerde ciddi IVK oranının kızlardan daha yüksek bulunması bu iddiayı destekleyebilir.

Gestasyon haftası <37 ve doğum ağırlığı <2500 g olan pretermlerde taburculuk öncesi mortalite ile cinsiyet ilişkisinin değerlendirildiği 32 çalışmayı içeren bir derlemede, 26 çalışmada erkek dezavantajı bildirilirken, 6 çalışmada farklılık saptanmamıştır (26). Prematüre bebeklerde erkek dezavantajı yıllar önce bildirilmiş olmakla birlikte, nedeni hala ayrıntılı olarak belirlenememiştir (5). İnsanlarda, erkek dezavantajının nedeni olabilecek fizyolojik mekanizmaları aydınlatmak için yapılan çalışma sayısı çok azdır. Stark ve ark. tarafından yapılan çalışmada, 24-28. haftalar arasında doğan erkek yenidoğanların; yaşamın ilk 24 saatinde, kızlara ve daha büyük gestasyon yaşındaki erkeklere göre daha fazla mikrovasküler kan akışına sahip olduğu gösterilmiştir (27). Bunun sonucunda, artmış mikrovasküler perfüzyonun düşük sistemik kan akımı ve hipotansiyona katkıda bulunması, daha fazla dolaşımsal sorunun görülmesine katkıda bulunabilir.

Deneysel bir çalışmada, preterm erkek kuzuların doğumdan sonraki 1. saatte dişilere göre kan pH düzeylerinin daha düşük; parsiyel arteriyel karbondioksit basıncı, kan laktat ve glukoz düzeyleri ile ortalama arteryel basınç değerlerinin daha yüksek saptandığı; bu farklııkların erkek mortalitesinin yüksek olması ile ilişkili olabileceği belirtilmiştir (32). Ayrıca erkek fetüslerdeki yüksek orandaki mortalitenin seks kromozomlarındaki farklılıktan kaynaklanabileceği de bildirilmiştir. Y kromozomu MSY'nin de dahil olduğu sadece 50 geni içerirken, $X$ kromozomu yaklaşı 3000 gen içermektedir. $Y$ kromozomunda gen tekrarı çoktur ve çoğunlukla non-fonksiyoneldir. Bu nedenle, $X Y$ kromozomuna sahip bireylerin XX kromozomuna sahip olanlardan X'e bağlı resesif hastalığa sahip olma olasılığı daha fazla

olduğu için, erkek çocukların kızlara göre daha sağlıksız olma riski yüksek olarak bildirilmiştir $(28,29)$.

Massachutes'te 1989- 1995 yılları arasındaki süreçte cinsiyete göre bebek mortalitesinin değerlendirildiği bir çalışmada, mortalitedeki \%50 azalmanın primer olarak erkek bebek mortalitesindeki azalmaya bağı olduğu bildirilmiştir. Erkek bebek morta- litesinde azalma en belirgin olarak < 30 gestasyon haftasındaki prematürelerde saptanmış ve en sık RDS'ye bağlı erkek ölümlerinde azalmaya bağlı olduğu bildirilmiştir. Bu azalmanın nedeni olarak antenatal steroid ve sürfaktan tedavisi gibi tedavilerin erkek bebekleri daha farklı etkileyebileceği söylenmiştir (30). Bizim çalışmamızda erkek ve kız bebeklerde RDS ve orta ağır BPD gibi solunumsal morbiditeler arasında farklılık saptanmadı. Bu durumun, antenatal steroid ve sürfaktan gibi tedavilerin, önceki süreçte erkeklerde fazla görülen solunumsal morbiditeleri azaltmış olmasından kaynaklanmış olabileceği düşünüldü.

Sonuç olarak çalışmamızda, mortalite ve IVK oranının, erkek preterm bebeklerde kızlardan daha yüksek olduğu gösterildi. Bu nedenle cinsiyet, preterm bebeklerin klinik izleminde göz önünde bulundurulması gereken faktörlerden biri olabilir. Ilaveten, pretermlerde morbidite ve mortalite ile cinsiyet ilişkisine dair kanıtların giderek artması, fizyopatolojik süreç ve neonatal olumsuz sonuçların azaltımasına yönelik cinsiyete özgü ek stratejiler geliştirimesi ile ilgili araştırmaların gerekliliğini göstermektedir.

"Çok Düşük Doğum Ağırlıklı Bebeklerde Cinsiyetin Prematüre Morbiditeleri ve Mortalite Üzerine Etkisi" isimli özgün araştırma makalesi "Jinekoloji - Obstetrik ve Neonatoloji Tıp Dergisi"ne yayınlanmak üzere gönderilmiştir. Araştırmanın dizaynı ve veri toplama Ş.I. ve M.B. tarafından yapılmıştır. Makalenin yazımı Ş.I. tarafından yapılmışıı. İstatistiksel analiz ve son gözden geçirme F.N.S. tarafından yapılmıştır. Gönderilen makalenin son halini tüm yazarlar onaylamıştır. Çalışmayla ilgili herhangi bir mali ya da çıkar çatışması yoktur.

Çalışmayı destekleyen organizasyon ve herhangi bir finansal ilişki yoktur. Yazarlar tüm verilerin sorumluluğunu almaktadır ve istendiği takdirde verileri dergi tarafından incelenmesine onam vermektedir. Gönderdiğim çalışma daha önceden yayınlanmamış ve yayımlanmak üzere herhangi bir dergiye değerlendirilmek üzere sunulmamıştır. Gönderdiğim çalışmada araştırma ve yayın etiğine uyulmuştur ve Jinekoloji - Obstetrik ve Neonatoloji Tıp Dergisi yayın politikası için uygundur.

\section{KAYNAKLAR}

1. Younge N, Goldstein RF, Bann CM,et al. Eunice Kennedy ShriverNational Institute of Child Healthand Human Development Neonatal Research Network. Survival and neurodevelopmental outcomes among periviable infants, N Engl J Med. 2017;376(7):617-628.

2. Horbar JD, Edwards EM, Greenberg LT, et al. Variation in 
performance of neonatal intensive care units in the United States. JAMA Pediatr. 2017;171(3):e164396.

3. Patel RM, Kandefer S, Walsh MC,et al. Eunice Kennedy Shriver National Institute of Child Health and Human Development Neonatal Research Network. Causes and timing of death in extremely premature infants from 2000 through 2011. N Engl J Med. 2015;372(4):331-340.

4. Stoll BJ, Hansen NI, Bell EF, et al. Eunice Kennedy Shriver National Institute of Child Health and Human Development Neonatal Research Network. Trends in care practices, morbidity, and mortality of extremely preterm neonates, 1993-2012. JAMA 2015;314(10):1039-1051.

5. Naeye RL, Burt LS, Wright DL, Blanc WA, Tatter D. Neonatal mortality, the male dis- advantage. Pediatrics 1971;48(6):902906.

6. Itabashi K, Horiuchi T, Kusuda S, et al. Mortality rates for extremely low birth weight infants born in Japan in 2005. Pediatrics 2009;123(2):445-450.

7. Ingemarsson I. Gender aspects of preterm birth. BJOG 2003;110(suppl 20):34-38. 8. Ray B, Platt MP. Mortality of twin and singleton live births under 30 weeks' gestation: a population-based study. Arch Dis Child Fetal Neonatal Ed. 2009;94(2): 140-143.

9. Rankin J, Pearce MS, Bell R, Glinianaia SV, Parker L. Perinatal mortality rates: adjusting

for risk factor profile is essential. Paediatr Perinat Epidemiol. 2005;19(1): 56-58.

10. Oygür N, Önal EE, Zenciroğlu A. Turkish Neonatal Society national guideline for the delivery room management. Turk Pediatri Ars. 2018;53(Suppl 1): S3-S17.

11. Köksal N, Aygün C, Uras N. Turkish Neonatal Society guideline on the management of patent ductus arteriosus in preterm infants. Turk Pediatri Ars. 2018;53(Suppl 1):S76-S87.

12. Özkan H, Erdeve Ö, Kanmaz Kutman HG. Turkish Neonatal Society guideline on the management of respiratory distress syndrome and surfactant treatment. Turk Pediatri Ars. 2018;53(Suppl 1):S45- S54.

13. Satar M, Engin Arısoy A, Çelik IH. Turkish Neonatal Society guideline on neonatal infections - diagnosis and treatment. Turk Pediatri Ars. 2018;53(Suppl 1): S88-S100.

14. Kültürsay N, Bilgen $H$, Türkyılmaz C. Turkish Neonatal Society guideline on enteral feeding of the preterm infant. Turk Pediatri Ars. 2018;53(Suppl 1): S109-S118.
15. Arsan S, Korkmaz A, Oğuz S. Turkish Neonatal Society guideline on prevention and management of bronchopulmonary dysplasia. Turk Pediatri Ars. 2018;53(Suppl 1): S138- S150.

16. Koç E, Yağmur Baş A, Özdek Ş, Ovalı F, Başmak H. Turkish Neonatal and Turkish Ophthalmology Societies consensus guideline on the retinopathy of prematurity. Turk Pediatri Ars. 2018;53(Suppl 1): S151-S160.

17. Bell MJ, Ternberg JL, Feigin RD, et al. Neonatal necrotizing enterocolitis. Therapeutic decisions based upon clinical staging. Ann. Surg. 1978; 187:1-7.

18. Papile LA, Munsick-Bruno G, Schaefer A. Relationship of cerebral intraventricular

hemorrhage and early childhood neurologic handicaps. J. Pediatr. 1983; 103:273-7.

19. Gujral IB, Stallones L, Gabella BA, Keefe TJ, Chen P. Sex differences in mortality after traumatic brain injury, Colorado 1994-1998. Brain Inj. 2006; 20:283-91.

20. Johnston MV, Hagberg H. Sex and the pathogenesis of cerebral palsy. Dev Med Child Neurol. 2007; 49:74-8.

21. Baenziger O, Jaggi JL, Mueller AC, Morales CG, Lipp HP, Lipp AE, et al. Cerebral blood flow in preterm infants affected by sex, mechanical ventilation, and intrauterine growth. Pediatr Neurol. 1994; 11:319- 24.

22. Gur RC, Gur RE, Obrist WD, Hungerbuhler JP, Younkin D, Rosen $A D$, et al. Sex and handedness differences in cerebral blood flow during rest and cognitive activity. Science 1982; 217:659-61.

23. Whitehouse, A. J. et al. Sex-specific associations between umbilical cord blood testosterone levels and language delay in early childhood. J Child Psychol Psychiatry 2012; 53:726-734.

24. Cho, J. \& Holditch-Davis, D. Effects of perinatal testosterone on infant health, mother- infant interactions, and infant development. Biol Res Nurs. 2014; 16:228-236.

25. Vu HD, Dickinson C, Kandasamy Y. Sex difference in mortality for premature and low birth weight neonates: a systematic review. Am J Perinatol. 2018;35(8):707-715.

26. Stark MJ, Clifton VL, Wright IM. Sex-specific differences in peripheral microvascular blood flow in preterm infants. Pediatr Res 2008; 63(04):415-419.

27. Ishak, N. et al. Sex differences in cardiorespiratory transition and surfactant composition following preterm birth in sheep. Am J Physiol Regul Integr Comp Physiol. 2012; 303: R778789. 
28. Di Renzo, G. C., Rosati, A., Sarti, R. D., Cruciani, L. \& Cutu- 30. Bhaumik U, et al. Narrowing of sex differences in infant li, A. M. Does fetal sex affect pregnancy outcome? Gend Med. mortality in Massachusetts. J Perinatol. 2004; 24:94 -99. 2007; 4:19-30.

29. Pongou, $R$. Why is infant mortality higher in boys than in girls? A new hypothesis based on preconception environment and evidence from a large sample of twins. Demography 2013; 50:421-444. 